Avrupa Bilim ve Teknoloji Dergisi

Özel Sayı, 34, S. 354-359, Mart 2022

(C) Telif hakkı EJOSAT'a aittir

Arasturma Makalesi

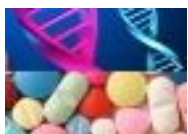

www.ejosat.com ISSN:2148-2683
European Journal of Science and Technology

Special Issue 34, pp. 354-359, March 2022

Copyright (C) 2022 EJOSAT

Research Article

\title{
Yakma Alın Kaynağıyla Birleştirilmiş S355JR Yapı Çeliklerinde ITAB'ın Karakterizasyonu
}

\author{
Gazi Emre Kocamanoğlu*1, Uğur Arabac1 ${ }^{2}$ ve Uğur Özdemir ${ }^{3}$ \\ 1* Gazi Üniversitesi, Fen Bilimleri Enstitüsü, Metalurji ve Malzeme Mühendisliği Bölümü, Ankara, Türkiye, (ORCID: 0000-0001-7125-425X), \\ g.kocamanoglu@hotmail.com \\ ${ }^{2}$ Gazi Üniversitesi, Teknoloji Fakültesi, Metalurji ve Malzeme Mühendisliği Bölümü, Ankara, Türkiye (ORCID: 0000-0003-4850-3275), uarabaci@gazi.edu.tr \\ ${ }^{3}$ Gazi Üniversitesi, Teknoloji Fakültesi, Metalurji ve Malzeme Mühendisliği Bölümü, Ankara, Türkiye (ORCID: 0000-0003-0521-4617), uozdemir@gazi.edu.tr
}

(2nd International Conference on Applied Engineering and Natural Sciences ICAENS 2022, March 10-13, 2022)

(DOI: 10.31590/ejosat.1082837)

ATIF/REFERENCE: Kocamanoğlu, G. E., Arabaci, U., Özdemir, U. (2022). Yakma Alın Kaynağıyla Birleştirilmiş S355JR Yapı Çeliklerinde ITAB'ın Karakterizasyonu. Avrupa Bilim ve Teknoloji Dergisi, (34), 354-359.

$\ddot{O} z$

Kaynak, günümüzde en yaygın olarak kullanılan birleştirme yöntemlerinden biridir. Bu nedenle kaynak yapılacak parçaların güvenliği, kaynaklı birleştirmelerin kullanıldığı tüm yapının güvenilirliği için büyük önem taşımaktadır. Termal dönüşümler ITAB'ın geometrisi ve kaynak nüfuziyetindeki bilgileri sağlar. Bununla birlikte termal dönüşümlerin kontrolü kaliteli bir kaynağın kritiğidir. Bu çalışmada kaynak işlemi için kaynak yöntemi olarak yakma alın kaynağı seçilmiştir. Kaynak işlemi için uygun boyutlara getirilen numunelere belirli aralıklarla delikler açılarak kaynak işlemi esnasında termokupl ve datalogger yardımıyla kaynak işlemi boyunca sıcaklık değerleri ölçülerek kayıt altına alınmıştır. Aynı zamanda kaynak esnasında termal kamera kullanılarak kaynak bölgesinin ulaşabildiği maksimum sıcaklık ölçümü yapılmıştır. Kaynaklı birleştirilen deney parçalarının birleştirme bölgelerinde meydana gelen mikroyapısal değişiklikler, 1ş̧k mikroskobunda ve taramalı elektron mikroskobunda (SEM) incelenmiştir. Mekanik özelliklerin belirlenmesi adına mikro sertlik ölçümleri alınmıştır.

Anahtar Kelimeler: Yakma alın kaynağı, Kaynaklanabilirlik, Termal analiz, Kaynak metalurjisi, Yapı çelikleri.

\section{HAZ Characterization of S355JR Structural Steels Joined by Flush-Butt Welding}

\begin{abstract}
Welding is one of the most widely used joining methods today. Therefore, the safety of the welded parts is of great importance for the reliability of the entire structure in which welded joints are used. Thermal conversions provide information on the geometry and weld penetration of the ITAB. However, control of thermal conversions is critical for the weld quality. In this study, flash butt welding was chosen as the welding method for the process. Holes were drilled at regular intervals in the samples to place thermocouples, which were brought to the appropriate dimensions for the welding process. During the welding process, the changing temperature values during the welding process were measured and recorded with the help of thermocouples and a datalogger. At the same time, the maximum temperature reached by the welding and HAZ region was measured by using a thermal camera during welding. The microstructural changes in the joining regions of the welded test pieces were examined under light microscope and scanning electron microscope (SEM). Microhardness measurements were taken to determine the mechanical properties.
\end{abstract}

Keywords: Flash-butt welding, Weldability, Thermal analysis, Welding metallurgy, Structural steels.

\footnotetext{
*Sorumlu Yazar: g.kocamanoglu@hotmail.com
} 


\section{Giriş}

Kaynak, günümüzde en yaygın olarak kullanılan birleştirme yöntemlerinden biridir. Bu nedenle kaynak yapılacak parçaların güvenliği, kaynaklı birleştirmelerin kullanıldı̆̆ı tüm yapı güvenilirliği için büyük önem taşımaktadır [1].

Yakma alın kaynağı günümüzde sık kullanılan bir kaynaklı birleştirme yöntemidir. Yakma alın kaynağında aynı kesit ölçülerine sahip olan birleştirilecek parçalar öncelikle hareketli çenelere sıkıştırılır. Kaynak akımı hareketli çeneler üzerinden malzemeye iletilir. Malzemeler birbirine temas ettirilerek, yüksek yoğunluktaki akımın geçişi sağlanır. Parçalar birbirlerine alın alına birleştirilir. Alın bölgesi denilen kısmın yakın çevresinde kaynak işlemi esnasında ortaya çıkan yüksek ısıdan etkilenerek belli başlı değișimlere uğrayan bir bölge meydana gelir. Bu bölge ısının tesiri altında kalan, ana malzemeden daha farklı özelliklere sahip olabilen ITAB bölgesidir [2,3].

Genellikle kaynaklı yapıda ITAB bölgesinin mekanik özellikleri çok etkilememesi adına dar olması istenir. Kaynak bölgesinin özellikle de kaynaklı yapının güvenliği için çok önemli olan ITAB'ın mekanik özelliklerinin belirlenebilmesi için kaynak yöntemi olarak yakma alın kaynağı seçilmiştir.

Yapı çelikleri bulunabilirliği ve kaynak kabiliyeti açısından önemlidir. Yapı çeliklerinin kaynak kabiliyeti oldukça iyidir. $\mathrm{Bu}$ amaçla kaynak işlemi numune olarak S355JR yap1 çeliği seçilmiştir.

Günümüzde birçok kaynak uygulamasında 1sının tesiri altındaki bölgenin ve kaynak edilen malzemedeki 1s1 enerjisi girdisinin kaynak kalitesine etkileri söz konusu olmaktadır. Kaynak esnasında kaynak bölgesi üzerindeki sıcaklık dağılımları kaynağın yapılmasına bağlı olarak ihtiyaçlar doğrultusunda önceden belirlenmesi gerekebilmektedir. Kaynaklı birleştirmelerdeki sıcaklık değişimine bağlı olarak oluşabilecek sorunlardan imalat aşamasına geçmeden önce haberdar olmak hem zaman hem maliyet hem de yapılan işin kalitesi yönünden oldukça önemlidir [4,5].

\section{Materyal ve Metot}

\subsection{Malzeme}

Deneysel çalışmalar için Ø20x100 mm boyutlarında S355JR yapı çeliği malzemesi kullanılmıştır.

Tablo 1. S355JR malzemesine ait kimyasal bileşim

\begin{tabular}{|c|c|c|c|c|c|c|}
\hline Malzeme & \multicolumn{6}{|c|}{ (\%) Kimyasal Bileşim } \\
\hline \multirow{2}{*}{ S355JR } & $\mathrm{C}$ & $\mathrm{Si}$ & $\mathrm{Mn}$ & $\mathrm{P}$ & $\mathrm{S}$ & $\mathrm{Cu}$ \\
\cline { 2 - 7 } & 0,24 & 0,16 & 1,30 & 0,045 & 0,0020 & 0,004 \\
\hline
\end{tabular}

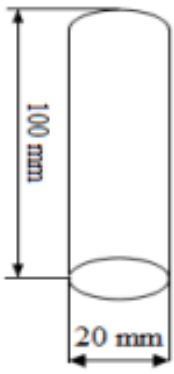

Şekil 1. Kaynak numunesinin ölçüleri

\subsection{Metot}

Numuneleri birleştirmek için yöntem olarak yakma alın kaynağı kullanılmıştır.

Yakma alın ray kaynağı yöntemi, kaynaklanacak ray uçlarının elektrik yardımıyla ısıtılıp ergitilerek birleştirilmesine dayanır. Ergiyene kadar ısıtılan ray uçları daha sonra birbirine doğru basınç yardımıyla birleştirilir. $\mathrm{Bu}$ yöntem hizalama, ilk yanma, ön 1sıtma, yakma, basma-şişirme ve sıyırma işlemlerinden oluşur. $\mathrm{Bu}$ kaynak yönteminde kullanılan ekipmanlar ise transformatör, elektrotlar, basma ve hidrolik düzeltme aparatlarıdır [6].

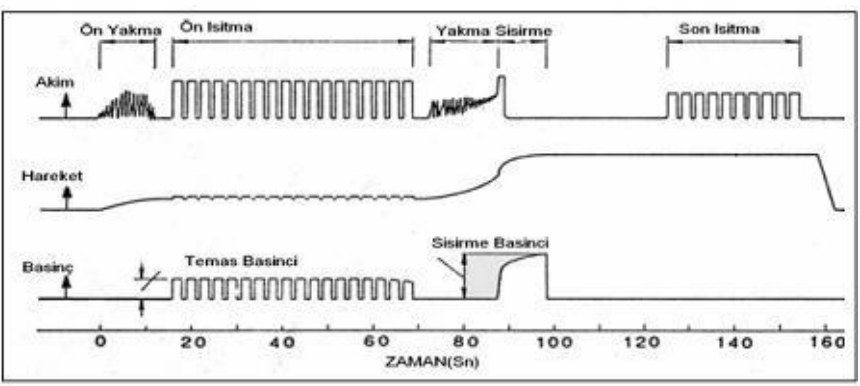

Şekil 2. Yakma alın kaynă̆ı prensibi [7].

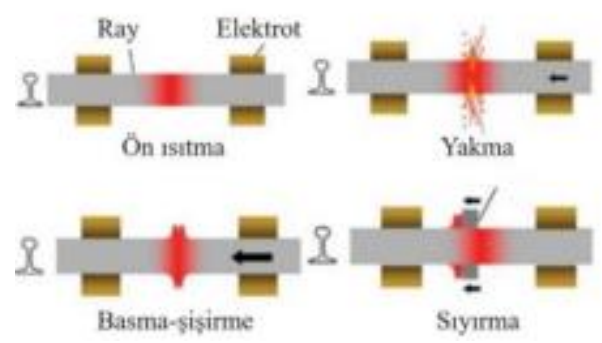

Şekil 3. Yakma alın kaynăğ işlem basamakları [8].

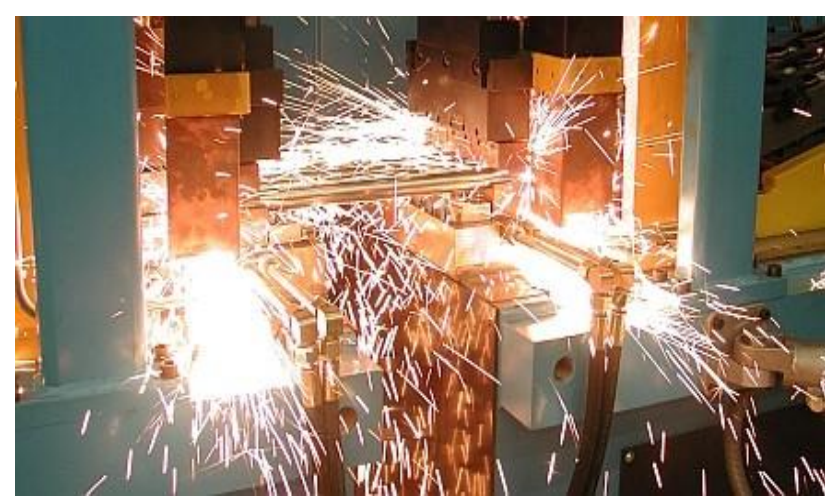

Şekil 4. Yakma alın kaynă̆ında örnek yanma işlemi [9].

Numuneler Şekil 1'de gösterildiği ölçülerde hazırlanarak, kaynak makinesine Şekil 5'de gösterildiği şekilde bağlanarak, Tablo 2'de verilen parametreler altında birleştirme işlemleri yapılmıştır. 


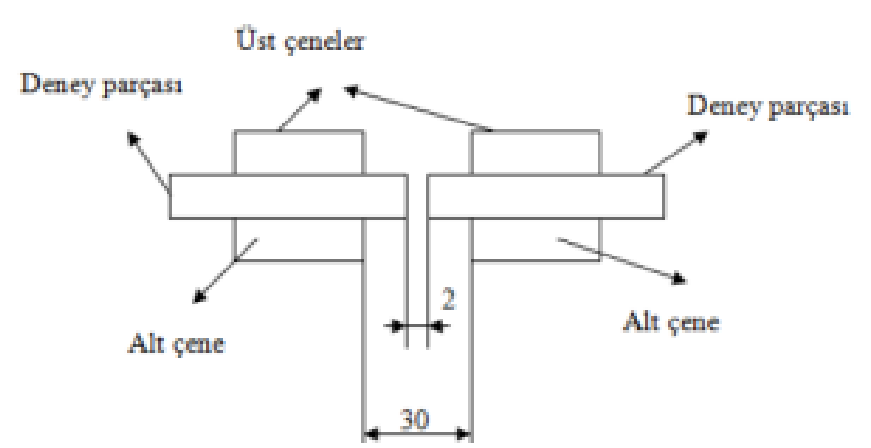

Şekil 5. Numunelerin çeneye bağlanması

Tablo 2. Kaynak işlemi için kullanılan parametreler

\begin{tabular}{|l|l|}
\hline Ön ısıtma zamanı (sn) & 3 \\
\hline Voltaj (V) & 3 \\
\hline Ampermetre (A) & 30 \\
\hline Vuruş Basıncı (Bar) & 2 \\
\hline Yığma Basıncı (Bar) & 3 \\
\hline Çene Sıkma Basıncı (Bar) & 3 \\
\hline Yı̆̆ma Akın Zamanı (sn) & 2 \\
\hline
\end{tabular}

\section{Deneysel Çalışmalar ve Sonuçlar}

\subsection{Sıcaklık Ölçümü}

Kaynak işlemine başlamadan önce malzeme makine haznesine uygun şekilde yerleştirildikten sonra önceden açılmış olan deliklere termokupl uçları yerleştirilmiştir. Kaynak esnasında ve kaynak gerçekleştikten sonra yani soğuma esnasında uygun datalogger ile sıcaklık değişimleri kaydedilmiştir.

Kaynak işlemi esnasında termokupllar ve datalogger ile sıcaklık ölçümü yapılırken eş zamanlı olarak termal kamera yardımıyla kaynak bölgesinin ulaştığı maksimum sıcaklığın tespiti yapılmaya çalışılmıştır. Kullanılan termal kamera ile kaynak işlemi boyunca video çekimi yapılmıştır.

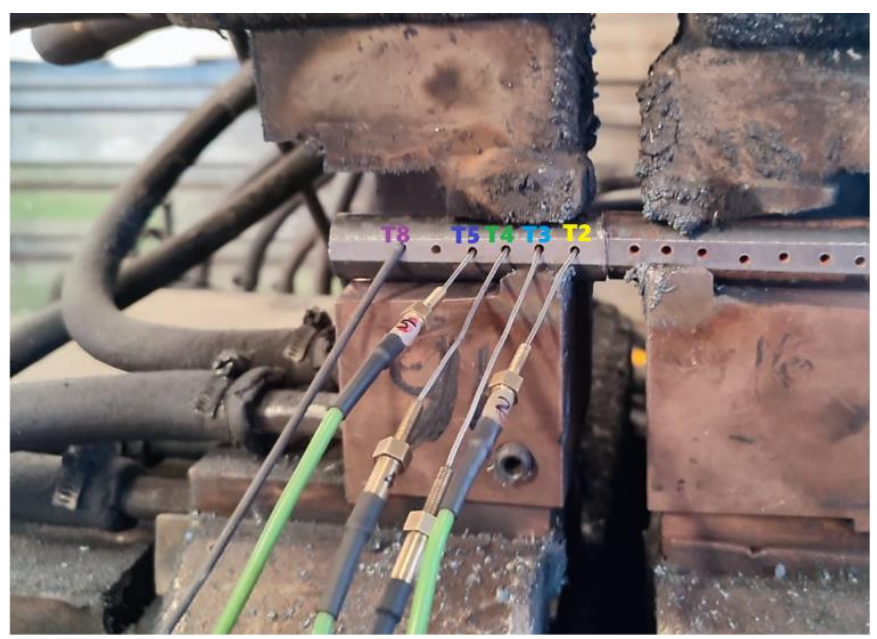

Şekil 6. Termokuplların numune üzerindeki dizilimleri

Şekil 6'da görüldüğü üzere kaynak yapılacak olan bölgeye yani alın bölgesine en yakın termokupl T2 ve en uzak olan termokupl T8 termokuplıdır. Grafiklerde bunlar göz önünde bulundurularak inceleme yapilmalidir.

Kaynak bölgesine en yakın termokuplın ölçebileceği maksimum sıcaklığın daha yüksek olması beklenmektedir.
Kaynak bölgesinden uzaklaştıkça ölçülen maksimum sıcaklık değerleri doğal olarak daha azdır.

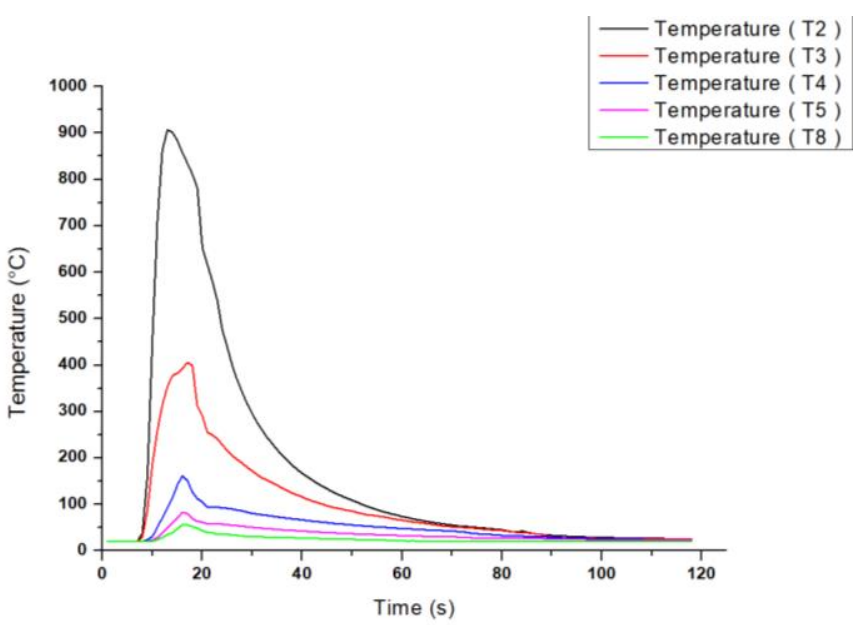

Şekil 7. Termokupllar ile ölçülen sıcaklık grafikleri

Şekil 7' de görüldüğü üzere kaynak bölgesine en yakın olan T2 termokuplı en yüksek sıcaklık değerlerini ölçmüştür ve soğuması daha fazla zaman almıştır.

Kaynak bölgesinden uzaklaştıkça ulaşılan pik sıcaklık değeri düşmüştür ve soğuma süresi kısalmıştır. Kaynak bölgesinden en uzak olan T8 Termokuplında ise sicaklık değişimi çok az olmuştur. $\mathrm{O}$ bölgede herhangi bir dönüşüm olup olmadığının yorumlanması ise mikroyapı incelemeleri esnasında tespit edilecektir.
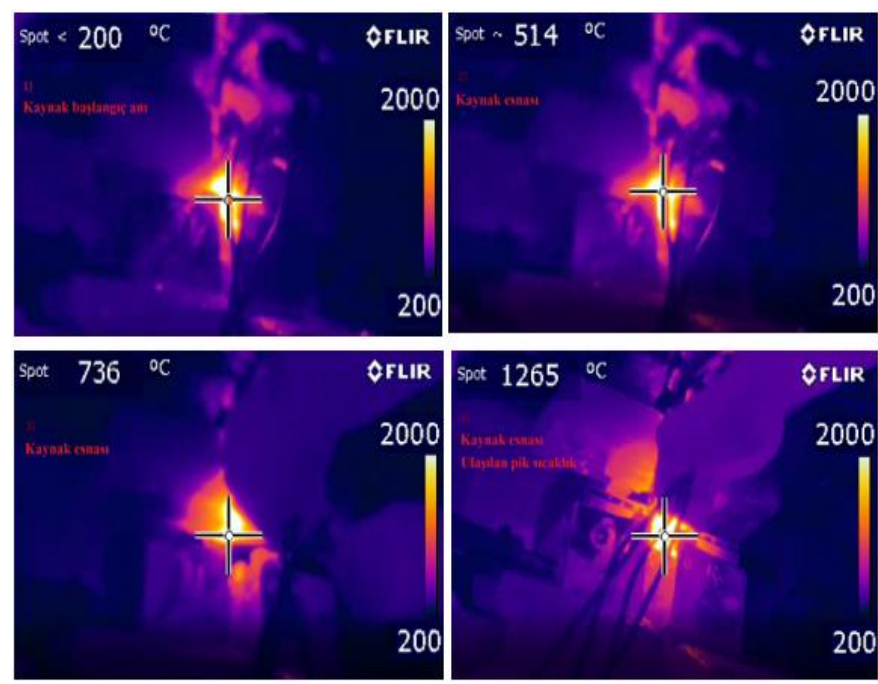

Şekil 8. Termal kamera görüntüleri

Termal kamera ile çekilen ekran görüntülerinden 4 adet görüntü Şekil 8'de gösterilmiştir. Alınan ekran görüntüleri kaynak esnasında çekilen videodan sırası ile alınmıştır. 4. Ekran görüntüsünden anlaşıldığı üzere kaynak bölgesi maksimum sıcaklığının $1265{ }^{\circ} \mathrm{C}$ olduğu tespit edilmiştir. Ulaşılan bu pik sıcaklıktan sonra kaynak işlemi tamamlanarak soğuma süreci başlamıştır.

\subsection{Sertlik Ölçümü}

$\mathrm{Bu}$ çalışmada sertlik ölçümleri için hazırlanan test numuneleri, mikro sertlik ölçüm cihazında 5 kgf yük altında 3 farklı bölgeden olmak üzere kaynak bölgesi "0" (referans) kabul edilerek her iki taraftan ITAB ve ana malzemeye ilerleyecek 
şekilde $2 \mathrm{~mm}$ aralıklarla ölçümler yapılarak HV cinsinden sertlik ölçümleri alınmıştır.

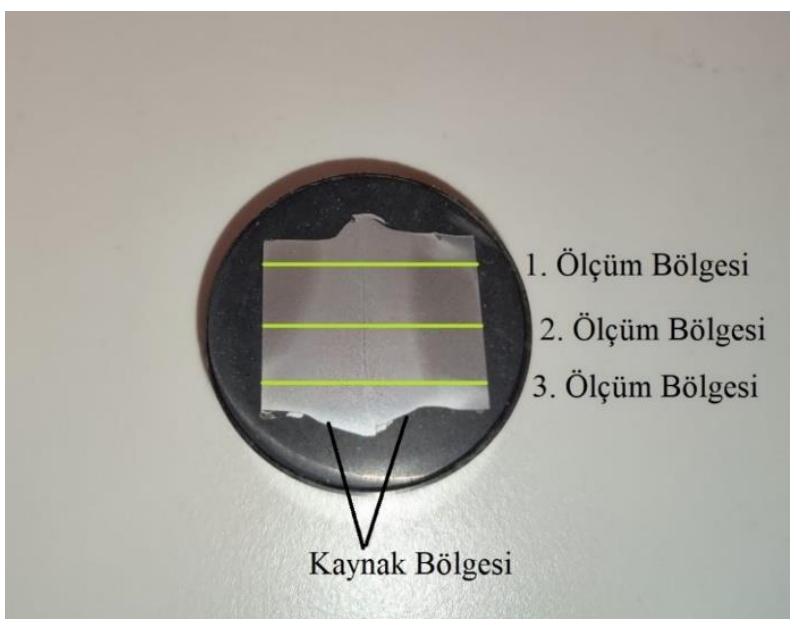

Şekil 9. Sertlik testinin yapıldı̆̆ bölgeler

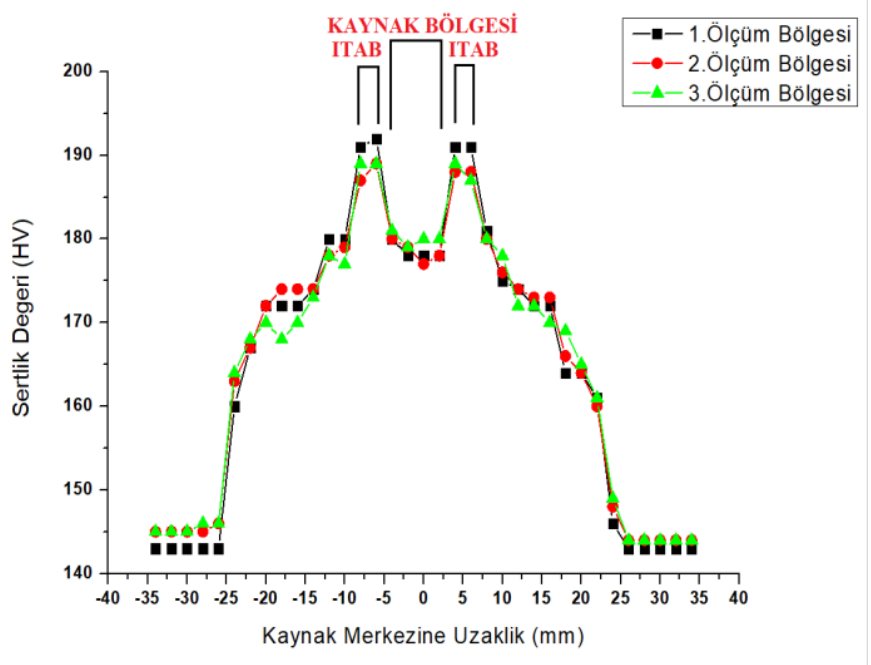

Şekil 10. Sertlik testi sonuçlarının grafiği

Şekil 10 'da görüldüğü üzere sıcaklık etkisinden en az etkilenen bölge de yani numunenin en uç bölgelerinde sertlik değerleri düşük çıkmıştır. Bu bölgeler dönüşüme uğramamıştır yani malzemenin kendi sertlik değerleridir. Kaynak bölgesine yaklaştıkça hızlı ısınma ve soğumanın etkisiyle malzeme yapısı değişerek sertleşme durumu meydana gelmiştir. Kaynak bölgesinde meydana gelen 1Sı türbülansı ve tane irileşmesinden dolayı sertlik değeri ITAB bölgesine göre daha düşük fakat ana metale göre daha yüksek çıkmıştır. Kaynak bölgesine yakın olan kısımda yani ısı etkisi altında kalan bölgede (ITAB) sertlik değeri kaynak bölgesine ve kaynak metaline göre daha yüksek çıkmıştır.

\subsection{Mikroyapı Sonuçları}

Malzemelerin iç yapılarının incelenmesini konu alan bilim dalına metalografi denir. Kalite kontrol, hasar tespiti gibi işlemler için malzemenin iç yapılarını incelemek gerekir. Metalografik muayene ile malzemenin üretim yöntemini, 1sıl işlem görüp görmediğini, mikro yapısını, mikro yapı kusurları incelenebilir. Metalografi deneylerinde malzemelerin mikro yapılarına 4 aşamada ulaşı1ır;

- Numune alma

- Zımparalama

- Parlatma

- Dağlama

Yapılan metalografi işlemlerinin sonucunda optik mikroskop altında numunelerden elde edilen mikro yapı görüntüleri aşağıda verilmiştir. Mikroyapı görüntülerinin alındığı bölgeler ayrıca Şekil 11'de numune üzerinden gösterilmiş̧tir.

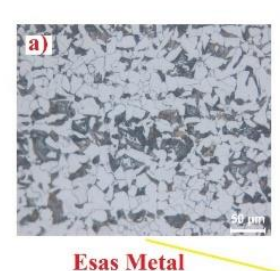

Esas Metal

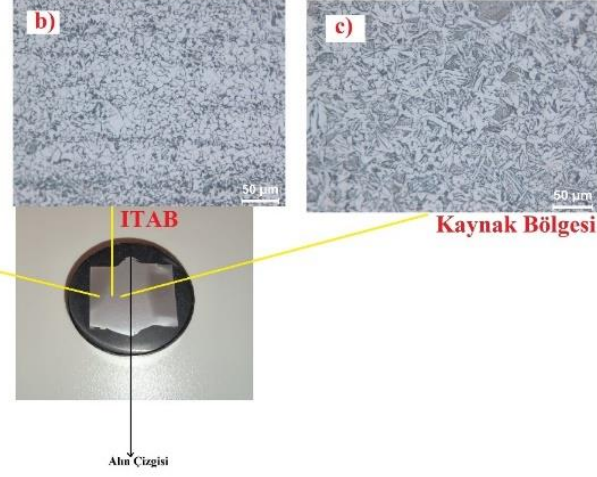

Şekil 11. Mikroyapıların alındiğl bölgelerin numune üzerinden gösterimi (20x büyütme) a) Esas metal b) ITAB c) Kaynak bölgesi

Şekil 11'de görüldüğü üzere a bölgesinde sıcaklık değişimi olmadığı için mikroyapı değişikliği olmamıştır. Yani herhangi bir dönüşüm meydana gelmemiştir.

B bölgesinde kaynak bölgesine yakın 1sıdan etkilenen bölge olan ITAB bölgesidir. Ana malzemeye göre perlit kolonilerinin küçüldüğü ve ferrit fazları arasında biraz daha homojen dağıldığı görülmektedir.

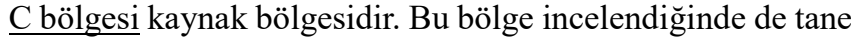
yapısının ince ve uzun şekilli dendritik tanelerden oluştuğu görülmektedir. Oluşan bu ince ve uzun şekilli taneler iğnemsi bir yapıya benzediği için asiküler ferrit yap1 olarak ta değerlendirilebilir.
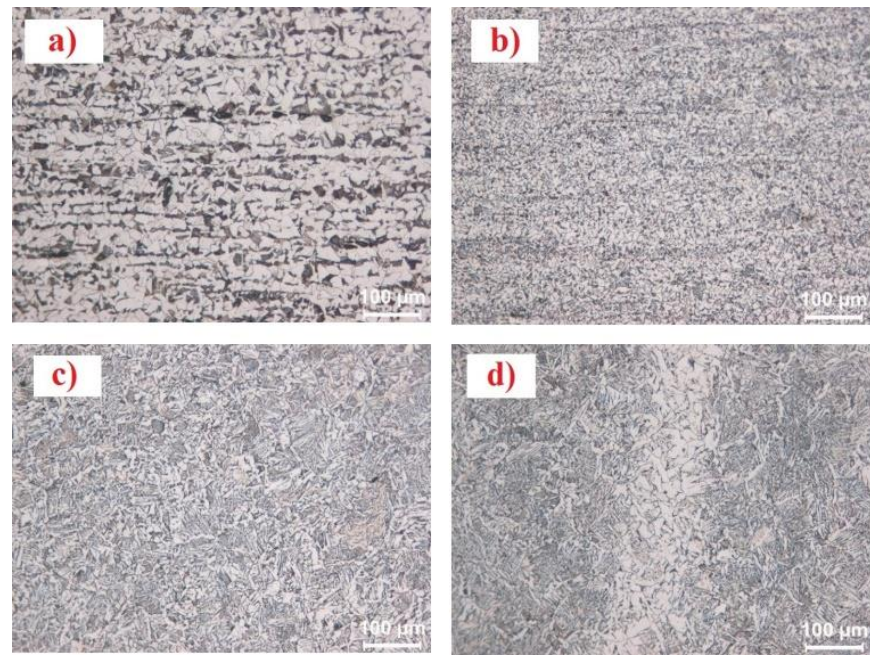

Şekil 12. Numune üzerinden alınan 10x büyütme görüntüleri a) Esas metal b) İnce taneli bölge c) Iri taneli bölge d) Kaynak bölgesi 

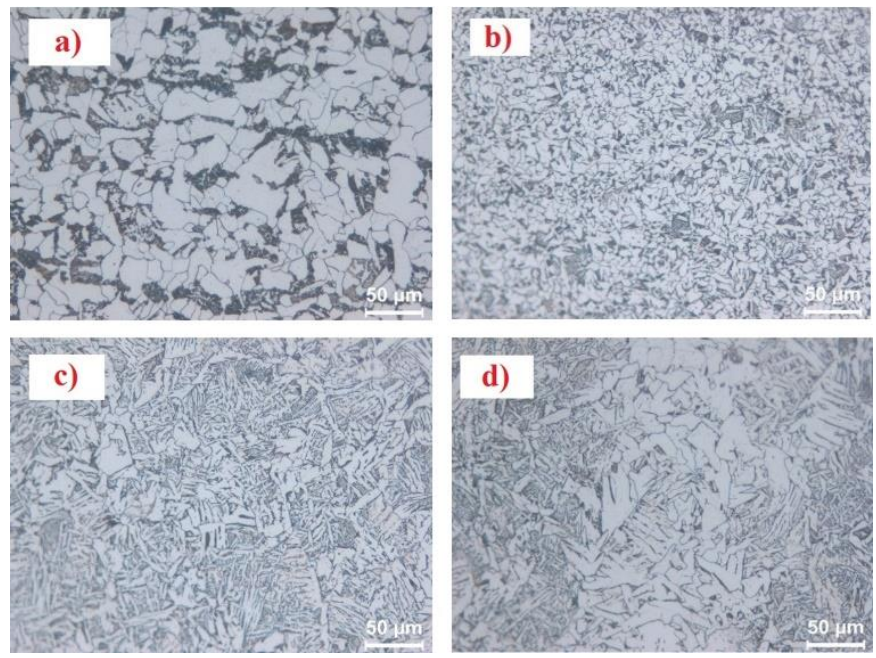

Şekil 13. Numune üzerinden alınan 20x büyütme görüntüleri a) Esas metal b) ITAB c) Kaynak bölgesi d) Kaynak bölgesi

Elde edilen mikroyapı analizlerinde oluşan yapıların daha detaylı görülebilmesi adına 20x büyütmede incelenerek, oluşan yapılar aşağıda gösterilmiştir.

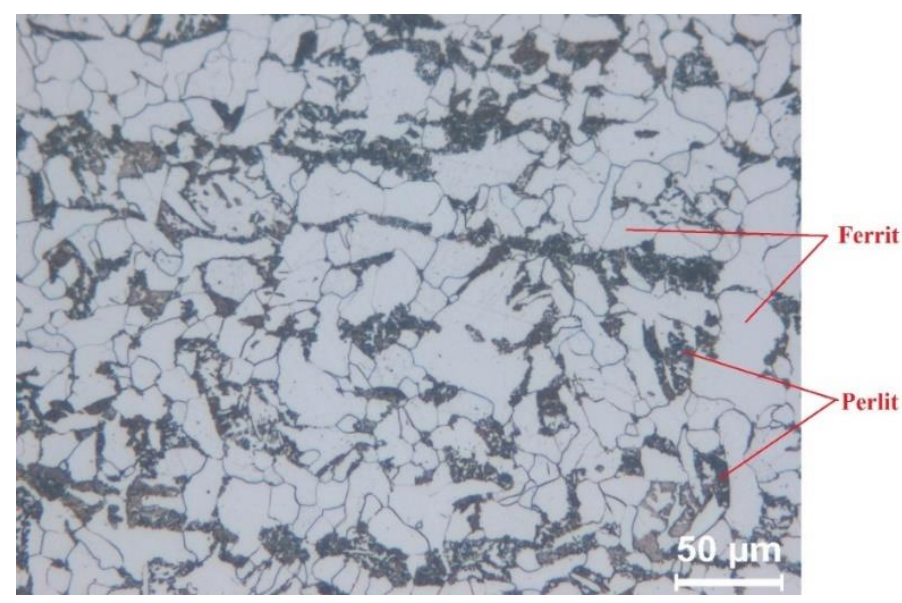

Şekil 14. Isl değişimine uğramamış bölgenin (esas metal) $20 x$ büyütmedeki görüntüsü

Şekil 14'de görüldüğü üzere kaynak bölgesinden en uzakta olan bölgede herhangi bir mikroyapı değişimi olmamıştır. Malzeme ana metalin mikroyapısı olan Ferrit ve Perlitik yapı karışımından oluşmaktadır.

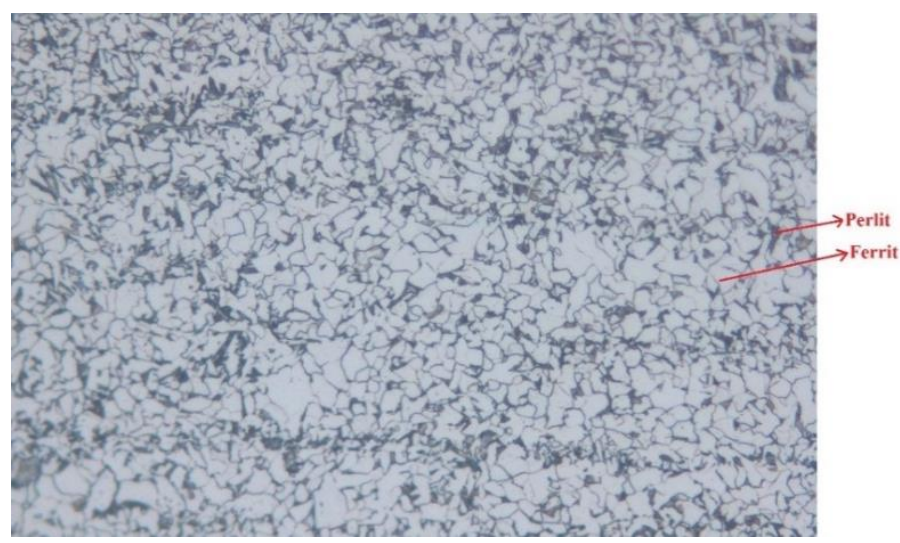

Şekil 15. Istnin tesiri altında kalan bölgenin (ITAB) $20 x$ büyütmedeki görüntüsü
Şekil 15'de görüldüğü üzere kaynak bölgesinde oluşan yoğun ısıdan ve hızlı soğumadan dolayı iç yapı değişikliğine uğrayan bir bölge meydana gelmektedir. Bu bölgede ana malzemeye göre perlit kolonilerinin daha küçüldüğü ve ferrit fazları arasında ana metale göre biraz daha fazla homojen dağıldığı görülmektedir.

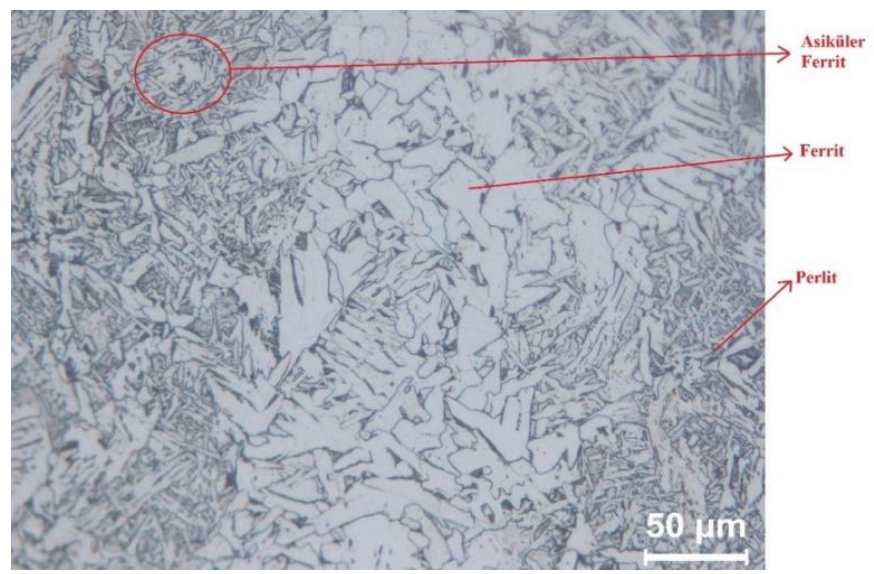

Şekil 16. Kaynak bölgesinin 20x büyütmedeki görüntüsü

Şekil 16'da görülen kaynak bölgesinin mikroyapısı incelendiğinde birleşme yüzeylerinde, yoğun ferritik yapı bulunurken, birleşme çizgisinin hemen yanında yer yer asiküler ferrit ve widmanstatten ferritten oluşan iri taneli bir yapı mevcuttur. Tane yapısının bu bölgelerde ince ve uzun şekilli dendritik tanelerden oluştuğu görülmektedir. Oluşan bu ince ve uzun şekilli taneler iğnemsi bir yapıya benzediği için asiküler ferrit yapı olarak da değerlendirilebilir.

\subsection{Sem Görüntüleri}

Deneysel çalışmalarda yakma alın kaynăg 1 yöntemiyle birleştirilen parçalardan standartlara uygun olarak tüm kaynak bölgesini ve ana metali temsil edebilecek şekilde olan numunelerden, mikroyapı değişikliklerini incelemek amacıyla farklı büyütmelerde görüntü alabilen Taramalı Elektron Mikroskop (SEM) (Scanning Electron Microscope) kullanılmıştır.

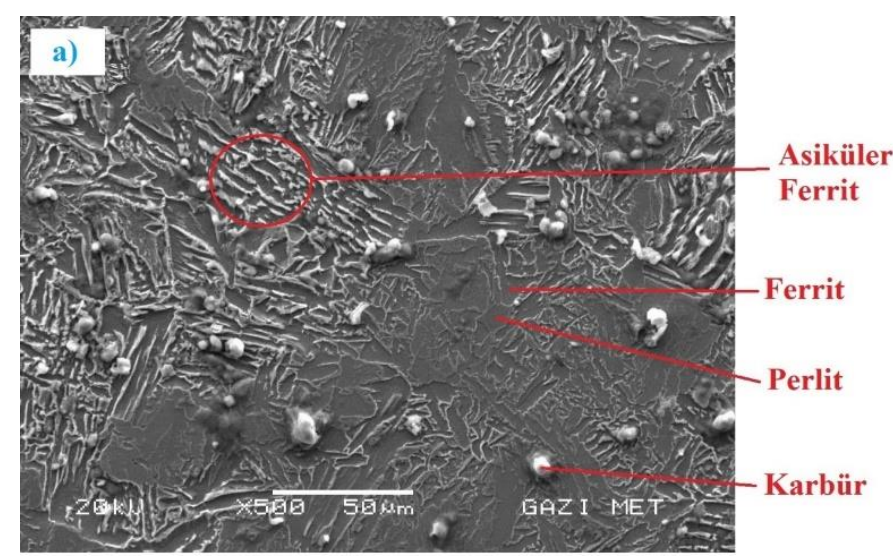

Şekil 17. Kaynak bölgesinin 500x büyütmedeki görüntüsü 


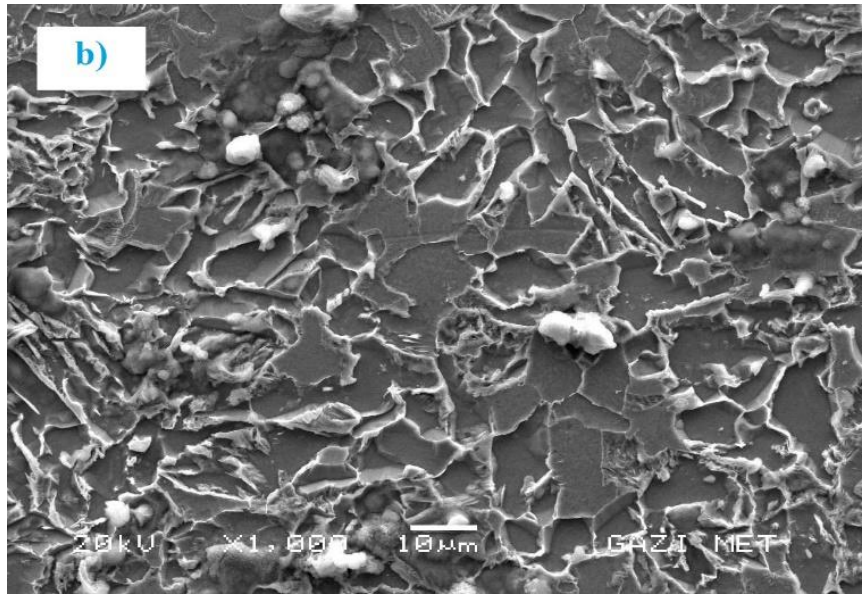

Şekil 18. Kaynak bölgesinin 100x büyütmedeki görüntüsü

Bölüm 3.3' de incelenen mikroyapı görüntülerinin daha net görünümleri taramalı elektron mikroskobu (SEM) ile elde edilmiştir. Kaynak bölgesindeki dendritik yapı bu görüntülerde net olarak görülmektedir.

\section{Genel Sonuçlar ve Tartışma}

\subsection{Genel Sonuçlar}

ITAB bölgesinde oluşan taneler 1s1 akış yönünün tersine olacak şekilde kaynak metali merkezine doğru yönlenmektedir.

Kaynak metalinde oluşan taneler farklı bir birleşim materyali kullanılmadığı için ana malzeme tanelerinin bir devamı şeklinde oluşmaktadır ve kaynak metali çok fazla gözenek, oksit vb. gibi olumsuzluk içermemektedir.

Malzemede meydana gelebilecek olan gözeneklilik gibi süreksizlerin yığma bölgelerine doğru ilerlediği ve işlem sonucunda uygun temizleme işlemlerinin yapılması halinde giderilebilecek şekilde olduğu gözlemlenmiştir.

Kaynak bölgesine etki eden basınç, direnç ve soğuma şartlarına bağlı olarak oluşan etkiler sebebiyle herhangi bir çatlak oluşumuna rastlanmamaktadır.

Kaynak merkezine ait bölge incelendiğinde birleşme yüzeyinde yoğun ferritik yapı bulunurken, birleşme çizgisinin hemen yanında asiküler ferrit ve widmanstatten ferritten oluşan iri taneli yapı mevcuttur. Geçiş bölgesinde yine bu yapılar varlığını korurken, daha homojen bir görünüme sahip olduğu görülmektedir.

\section{2. Öneriler ve Tartışma}

Deneysel çalışma kısmında kaynak parametrelerini sabit tutarak kaynak sırasının planı değiştirilmeden deney tamamlanmıştır. $\mathrm{Bu}$ çalışma farklı kaynak parametreleri kullanılarak karşılaştırma şeklinde bir çalışma yapılabilir.

$\mathrm{Bu}$ çalışmada numuneler herhangi bir açı olmadan direkt olarak birleştirme yapılmıştır. Farklı açılarda birleştirme yapılarak inceleme sağlanabilir.

Farklı malzemeler (paslanmaz çelik, yüksek karbonlu çelik, alaşımlı çelikler, vb.) kullanarak benzer çalışmalar yapılabilir.

Makine tasarımlarında sıkça karşılaşılan; farklı malzemelerin ve farklı geometrilerin kaynak edilme durumu göz önüne alınarak tasarım değiştirilebilir.
Malzemelerin kalınlıkları ile orantılı 1sı girdisi ve değişen kaynak parametreleri baz alınarak deney tekrarlanabilir.

Kaynaklı birleştirmelerin eğme, kırma gibi mekanik testleri için modeller oluşturulup analizi yapılabilir.

\section{Teşekkür}

Yapılan bu çalışmanın maddi açıdan desteklenmesine olanak sağlayan Gazi Üniversitesi Bilimsel Araştırma Projeleri (BAP) Komisyon Başkanlığına (Proje No: FGA-2021-7011) teşekkür ederim.

\section{Kaynakça}

[1] Kökçe, Y. (2002). Demiryolu taşıt ve raylarının üretim ve tamir-bakımında uygulanan kaynak yöntemlerinin karşılaştırmal olarak incelenmesi, (yüksek lisans tezi), İstanbul Teknik Üniversitesi, İstanbul, Türkiye.

[2] Onay, M. (2011). Demiryollarında Alüminotermit Kaynak ile Yakma Alın Kaynak Yöntemlerinin Teknik ve Ekonomik Yönden Karşılaştırılması, (yüksek lisans tezi), Bahçeşehir Üniversitesi, İstanbul, Türkiye.

[3] Fischer, S., Eller, B., Kada, Z. and Nemeth, A. (2015). “Railway construction”, ISBN: 978- 615-5298-69-1.

[4] Kuday, N. ve Ertürk, İ. (1997). Raylarda Yakma Alın Kaynağ l, TMMOB Makina Mühendisleri Odası Kaynak Teknolojisi 1. Ulusal Kongresi, 13-15 Kasım 1997, Ankara, Türkiye.

[5] Esveld, C. (2001). Modern Railway Track, MRT Productions, Hollanda.

[6] M. Fujii, H. Nakanowatari and K. Nariai, "Rail flash butt welding technology, ” JFE Technical Report, no. 20, pp. 159163, 2015.

[7] E. Turan, M. Dursunlar and H. Çuğ, "Investigation of welding residual stress in flash-butt joint of R260 grade rail," Fourth International Railway Systems Symposium (ISERSE'18), Karabük, Türkiye, 2018, pp. 735-733.

[8] J. Breckling, Ed., The Analysis of Directional Time Series: Applications to Wind Speed and Direction, ser. Lecture Notes in Statistics. Berlin, Germany: Springer, 1989, vol. 61.

[9] M.E. Turan, "R260 kalite tren raylarında kalıntı gerilmenin belirlenmesi ve bunun mekanik özelliklere etkisinin incelenmesi," M.Sc. dissertation, Dept. Metallurgy and Materials Eng., Karabük Univ., 2015. 